\title{
Optimisation of aggregate gradation of ultra-high-performance concrete based on the modified compressible packing model
}

\section{Jinzhen Li}

School of Materials Science and Engineering, Nanchang University, Nanchang, Jiangxi, China

\section{Lei Huang}

School of Materials Science and Engineering, Nanchang University, Nanchang, Jiangxi, China

\section{Shaowen Huang}

School of Materials Science and Engineering, Nanchang University, Nanchang, Jiangxi, China (corresponding author: huangsw@163.com)

The compressible packing model (CPM), which is a method for designing aggregate gradation, was used to calculate the packing density of quartz aggregate. The aggregate gradation of ultra-high-performance concrete (UHPC) was optimised using the CPM. The number of interfaces between the aggregates and cement was determined using Image-Pro Plus software. The CPM modified using the equation $Y=0.60073 X+0.20551$ was found to calculate the packing density of quartz aggregate accurately. The compressive strength of the UHPC was found to be positively correlated with the packing density of the aggregate: an increase in the packing density led to a compressive strength increase from $97.9 \mathrm{MPa}$ to $124.1 \mathrm{MPa}$, an increase of $26.7 \%$. The flexural strengths of the material was found to be sensitive to the number of interfaces: the smaller the number of interfaces, the greater the flexural strength. The specimen with an interface length of $5.56 \mathrm{~mm} / \mathrm{mm}^{2}$ had the smallest flexural strength $(21.5 \mathrm{MPa})$ and the specimen with an interface length of $3.596 \mathrm{~mm} / \mathrm{mm}^{2}$ had the largest flexural strength (25.9 MPa). It is recommended that, when designing aggregate gradation, a gradation with high density should be selected and the proportion of small-size aggregates should not be too large.

\section{Notation}

$a_{j i} \quad$ loosening effect coefficient

$b_{j i} \quad$ wall effect coefficient

$d_{i} \quad$ particle size of $i$

$d_{j} \quad$ particle size of $j$

$d_{\text {max }} \quad$ largest particle size

$d_{\text {min }} \quad$ smallest particle size

$K \quad$ compaction index

$y \quad$ volume fraction

$\beta \quad$ virtual packing density

$\gamma \quad$ calculated packing density

$\phi \quad$ real packing density

\section{Introduction}

Ultra-high-performance concrete (UHPC) is widely used due to its excellent mechanical properties and durability (Chen et al., 2017; Xu et al., 2018). Optimisation of the performance of UHPC is still a research focus in the field of concrete science (Arora et al., 2019; Vincler et al., 2019), in which optimisation of the aggregate gradation plays an important role. In 1999, De Larrard (1999) proposed the compressible packing model (CPM), which is a mathematical model for calculating packing density based on a large number of experiments. The model can calculate packing density with high accuracy (Achour et al., 2019; Yuan et al., 2020) and is thus widely used in concrete design (Han et al., 2016; Moghaddam and Baaj, 2018; Van Der Putten et al., 2017).

To date, aggregate gradation theories are mainly the theoretical maximum density of the curve and particle interference theory. Fuller and Thompson (1907) proposed the theoretical maximum density of the curve, considering that aggregates with different particle sizes are combined in a certain proportion. Theoretically, aggregates have high density and low porosity. The particle interference theory, proposed by Weymouth (1933), is based on filling theory; its purpose is to obtain the maximum compactness of particles. During the long period of the development of concrete science, scientists have further optimised both theories (Bolomey, 1927; Talbot et al., 1923). Shilstone (1990) and Shilstone and Shilstone (2002) proposed a coarse factor and a work factor to improve workability by controlling these two parameters. These theories all assume that aggregates are spherical particles without considering their actual shapes (Ghasemi et al., 2018; Kwan et al., 1999; Maerz, 2004), even though the compactness of particles of the same size but different shapes will be very different (Thirumalaiselvi et al., 2018). The shape of the aggregate will clearly affect the optimal combination of aggregate but, due to the complexity of the shape factor, there is no unified theory to 


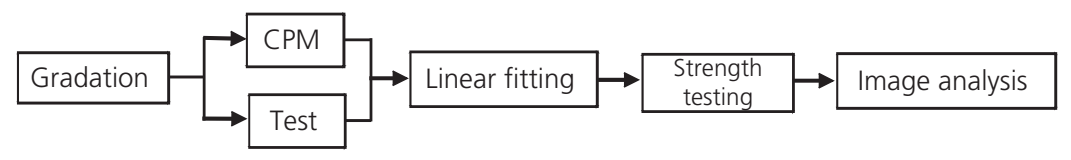

Figure 1. Technical route of this study

Table 1. Calculation formulae (Bala et al., 2019; Roquier, 2017)

\begin{tabular}{|c|c|}
\hline & Formula \\
\hline Particle size, $d_{j}$ & $\log _{10} d_{j}=\left(\log _{10} d_{\min }+\log _{10} d_{\max }\right) / 2$ \\
\hline Loosening effect coefficient, $a_{j i}$ & $a_{j i}=\sqrt{1-\left(1-\frac{d_{i}}{d_{j}}\right)^{1.02}}$ \\
\hline Wall effect coefficient, $b_{j i}$ & $b_{j i}=1-\left(1-\frac{d_{j}}{d_{i}}\right)^{1.50}$ \\
\hline Calculated packing density, $\gamma$ & $\gamma=\gamma_{2}=\frac{\beta_{2}}{1-\left\{1-\beta_{2}+b_{21} \beta_{2}\left[1-\left(1 / \beta_{1}\right)\right]\right\} y_{1}-\left[1-\left(a_{23} \beta_{2} / \beta_{3}\right)\right] y_{3}}$ \\
\hline & $\gamma=\min \left(\gamma_{i}\right) \quad 1 \geq i \geq 3$ \\
\hline Compaction index & $K=\sum_{i=1}^{n} K_{i}=\sum_{i=1}^{n} \frac{\gamma_{i} / \beta_{i}}{(1 / \phi)-\left(1 / \gamma_{i}\right)}$ \\
\hline
\end{tabular}

define the shape factor of aggregates (Abyaneh et al., 2013; Mora and Kwan, 2000).

In the work described in this paper, the CPM was modified, by the linear fitting method, to eliminate the influence of the shape factor on the packing density so that the accuracy of the calculation is greatly improved. The route taken in this study is illustrated in Figure 1. First, experimental and calculated values of the packing density of quartz sand were compared. The calculated values were then corrected by linear fitting. UHPC was prepared using quartz sand with different packing densities. The flexural and compressive strengths of UHPC specimens were measured to study the relationship between strength and packing density. Finally, the relationship between strength and particle size was studied using image analysis. A new method for designing aggregates for UHPC was developed.

\section{Experimental details}

The CPM

Three combinations of quartz sand particles were studied. The ternary calculation formula is shown in Table 1. The compaction index $(K)$ of the packing density of the quartz sands was in accordance with the pouring packing process, so $K=4 \cdot 1$ (Table 2). UHPC was prepared using quartz sand of three different particle sizes $(1 \cdot 18-0.60 \mathrm{~mm}, 0.60-0.30 \mathrm{~mm}$ and $0.30-0.15 \mathrm{~mm})$. The measured packing densities of the three sands are listed in Table 3. Substituting these data into the formula shown in Table 1, the packing densities of the different particle size combinations were calculated.
Table 2. Values of compaction index K (De Larrard, 1999)

\begin{tabular}{lc} 
Packing process & $\boldsymbol{K}$ \\
\hline Pouring & $4 \cdot 10$ \\
Vibration & $4 \cdot 75$ \\
Vibration + compression & $9 \cdot 00$ \\
Slurry & $6 \cdot 70$ \\
\hline
\end{tabular}

Table 3. Measured packing densities

$\begin{array}{lc}\text { Particle size range: } \mathbf{m m} & \text { Packing density } \\ 1 \cdot 18-0.60 & 0.5616 \\ 0.60-0.30 & 0.5352 \\ 0.30-0.15 & 0.4914\end{array}$

\section{Raw materials}

White Portland cement (P.W52.5) used in this study was provided by Jiangxi Yinshang Co., Ltd and silica fume was provided by Elkem (Shanghai) (silica content $\geq 95 \%$ ). The quartz powder of 325 mesh and the quartz sands of 20-40 mesh and 40-70 mesh were produced in Guangxi. Polycarboxylate water reducer (SD-600P-02), with a waterreducing rate of more than $25 \%$, was provided by Shanghai Sanrui Polymer Materials Co., Ltd.

\section{Experimental method}

The cement:silica fume:quartz sand:quartz powder ratio was $0 \cdot 9: 0 \cdot 1: 1: 0 \cdot 2$ and the amount of water reducer used was $1 \cdot 5 \%$ 
Table 4. Calculated and real packing densities of different sand gradations

\begin{tabular}{|c|c|c|c|c|c|}
\hline \multirow[b]{2}{*}{ Sample number } & \multicolumn{3}{|c|}{ Sand proportion } & \multicolumn{2}{|c|}{ Packing density } \\
\hline & $1.18-0.60 \mathrm{~mm}$ & $0.60-0.30 \mathrm{~mm}$ & $0.30-0.15 \mathrm{~mm}$ & Calculated & Actual \\
\hline 1 & 0.35 & 0.40 & 0.25 & 0.5990 & 0.5567 \\
\hline 2 & 0.35 & 0.45 & 0.20 & 0.5923 & 0.5593 \\
\hline 3 & 0.30 & 0.50 & 0.20 & 0.5876 & 0.5558 \\
\hline 4 & $0 \cdot 30$ & 0.55 & 0.15 & 0.5804 & 0.5538 \\
\hline 5 & $0 \cdot 30$ & 0.60 & 0.10 & 0.5734 & 0.5524 \\
\hline 6 & 0.25 & 0.65 & 0.10 & 0.5689 & 0.5481 \\
\hline 7 & $0 \cdot 20$ & 0.70 & $0 \cdot 10$ & 0.5645 & 0.5460 \\
\hline 8 & $0 \cdot 10$ & 0.80 & $0 \cdot 10$ & 0.5559 & 0.5390 \\
\hline 9 & 0.55 & $0 \cdot 10$ & 0.35 & 0.6004 & 0.5645 \\
\hline 10 & 0.45 & 0.25 & 0.30 & 0.5997 & 0.5642 \\
\hline 11 & 0.40 & 0.40 & 0.20 & 0.5972 & 0.5655 \\
\hline 12 & 0.50 & 0.15 & 0.35 & 0.5966 & 0.5661 \\
\hline 13 & 0.70 & 0.05 & 0.25 & 0.6271 & 0.5790 \\
\hline 14 & 0.50 & 0.30 & 0.20 & 0.6072 & 0.5667 \\
\hline 15 & 0.50 & 0.20 & 0.30 & 0.6036 & 0.5675 \\
\hline 16 & 0.60 & 0.30 & $0 \cdot 10$ & 0.6019 & 0.5722 \\
\hline 17 & $0 \cdot 80$ & $0 \cdot 10$ & $0 \cdot 10$ & 0.6020 & 0.5730 \\
\hline 18 & $0 \cdot 15$ & 0.25 & 0.60 & 0.5411 & 0.5277 \\
\hline
\end{tabular}

of the mass of cementitious material. UHPC was prepared by changing the ratio of the three quartz sands. The dry materials were mixed for $2 \mathrm{~min}$ in a mortar mixer. After adding the water, the mixture was mixed for a further $8 \mathrm{~min}$. Mortar specimens of size $40 \times 40 \times 160 \mathrm{~mm}$ were prepared. Tests were performed after curing the samples for a specified time.

The strengths of the specimens at $28 \mathrm{~d}$ were tested according to Chinese standard GB/T 17671 (CNS, 1999) and the packing densities of the specimens were tested according to Chinese standard GB/T 14684 (CNS, 2011). After crushing and polishing the samples, they were placed under a microscope, magnified five times and photographed. To count the number of aggregate interfaces, the photographs were processed using Image-Pro Plus software.

\section{Results and discussion}

\section{Actual and calculated packing densities}

\section{Actual packing density}

Eighteen different gradations of quartz sand were tested and their packing densities were determined by the CPM and testing. Table 4 shows the mass ratios of the three aggregates and the calculated and measured packing densities. As shown in the table, the calculated and real packing densities were not in complete agreement and this is because the CPM treats particles as spheres (i.e. it does not consider particle shape) (Prudêncio et al., 2013). The results were fitted using the least-squares method. The fitted graph is shown in Figure 2 and the fitting equation and correlation coefficient (adjusted $R^{2}$ ) are shown in Table 5. The correlation coefficient between the linear fitting equation and the experimental data was determined to be 0.95276 . The linear fitting equation was

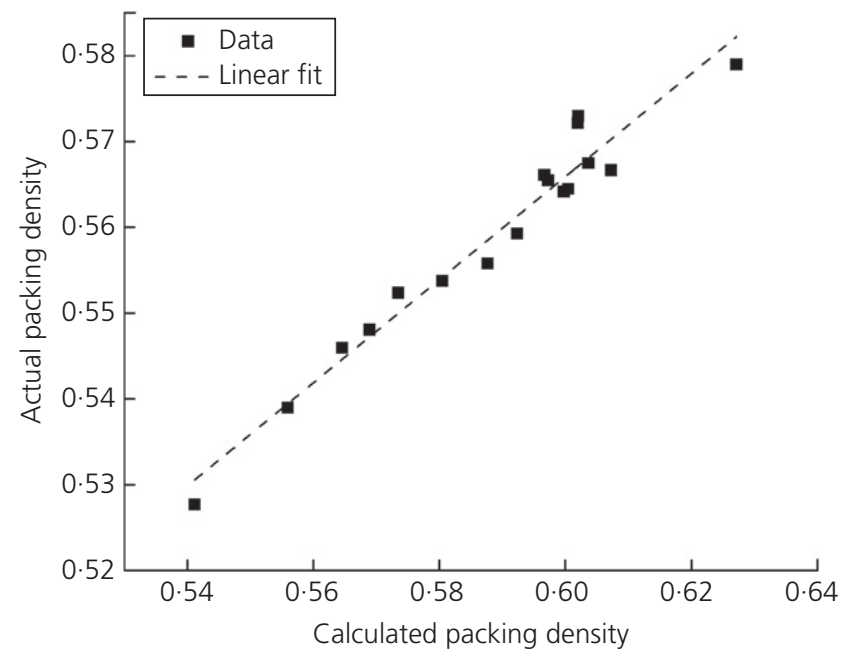

Figure 2. Linear fit of the calculated packing density

Table 5. Fitting equation and correlation coefficient

\begin{tabular}{|lc|}
\hline Equation & Adjusted $\boldsymbol{R}^{2}$ \\
$Y=0.60073 X+0.20551$ & 0.95276
\end{tabular}

thus very accurate for correcting the calculated packing density as it eliminated the error caused by the shape of the particles. Therefore, the calculated value was corrected by the equation $Y=0 \cdot 60073 X+0 \cdot 20551$ for the final packing density, where $X$ represents calculated packing density and $Y$ represents actual packing density. Correcting the CPM with the linear fit was the key to accurate calculation of the packing density. 


\section{Packing density calculated using Matlab}

After substituting the modified equation ( $Y=0.60073 X+$ 0.20551) into the CPM formula, the packing densities of all combinations of the three quartz sands were calculated using Matlab. The results are shown in Figure 3. Considering the contours in the triangle, it can be seen that the influence of the three particle sizes on the packing density was in the order $1 \cdot 18-0.60 \mathrm{~mm}>0 \cdot 30-0.15 \mathrm{~mm}>0.60-0.30 \mathrm{~mm}$. The white area in Figure 3 shows the sand combinations with the highest packing density. Particles of size $1 \cdot 18-0.60 \mathrm{~mm}$ occupy the main part of the mix, with appropriate amounts of the other two particle sizes. The packing density of the quartz sand was thus optimised.

\section{Relationship between packing density and strength}

UHPC specimens were prepared using quartz sands with different gradations and their flexural and compressive strengths were measured at $28 \mathrm{~d}$. The compressive strength results are shown in Figure 4 and the flexural strength results are shown in Figure 5. Comparison of Figure 4 with Figure 3 shows that the compressive strength had a good correlation with the packing density of the quartz sand: the higher the sand packing density, the higher the compressive strength of the UHPC. In particular, the areas showing high density and high compressive strength were in very good agreement. These figures also indicate that, with an increase in packing density, the compressive strength of the UHPC increased from $97.9 \mathrm{MPa}$ to $124.1 \mathrm{MPa}$ - an increase of $26.7 \%$. For the samples with a compressive strength greater than $120 \mathrm{MPa}$, the proportion of $0 \cdot 60-0 \cdot 30 \mathrm{~mm}$ particles was less than $10 \%$ and the proportion of particles of size $1 \cdot 18-0.60 \mathrm{~mm}$ was $65-80 \%$. Therefore, it is possible to enhance compressive strength by optimising the packing density of quartz sand, which is a new way of optimising concrete preparation.

Comparison of Figure 5 with Figure 3 shows that when the packing density of the quartz sand was higher than $0 \cdot 57$, the flexural strength of the sample was 23-24 MPa. However, the maximum flexural strength (the white area in Figure 5) was 25-26 MPa, which was not the area of the triangle with the highest density. The gradation of the white area was approximately $50-60 \%$ of $0 \cdot 60-0 \cdot 30 \mathrm{~mm}$ particles and approximately $10-13 \%$ of $0 \cdot 30-0 \cdot 15 \mathrm{~mm}$ particles. This result shows that there was no linear positive correlation between the packing density of the quartz sand and the flexural strength of the UHPC, but it had a certain degree of correlation with the sand gradation.

\section{Image analysis}

Three typical grading schemes of quartz sand were designed (C1, C2 and $\mathrm{C} 3$ ) and the packing densities and strengths of UHPC made with the three gradations were tested. The gradations of the quartz sand and the test data are shown in Table 6. The samples were placed under a microscope and 20 photographs of different areas were taken. Image processing software was used to grab the area of the aggregate; the photo processing process is shown in Figure 6 .

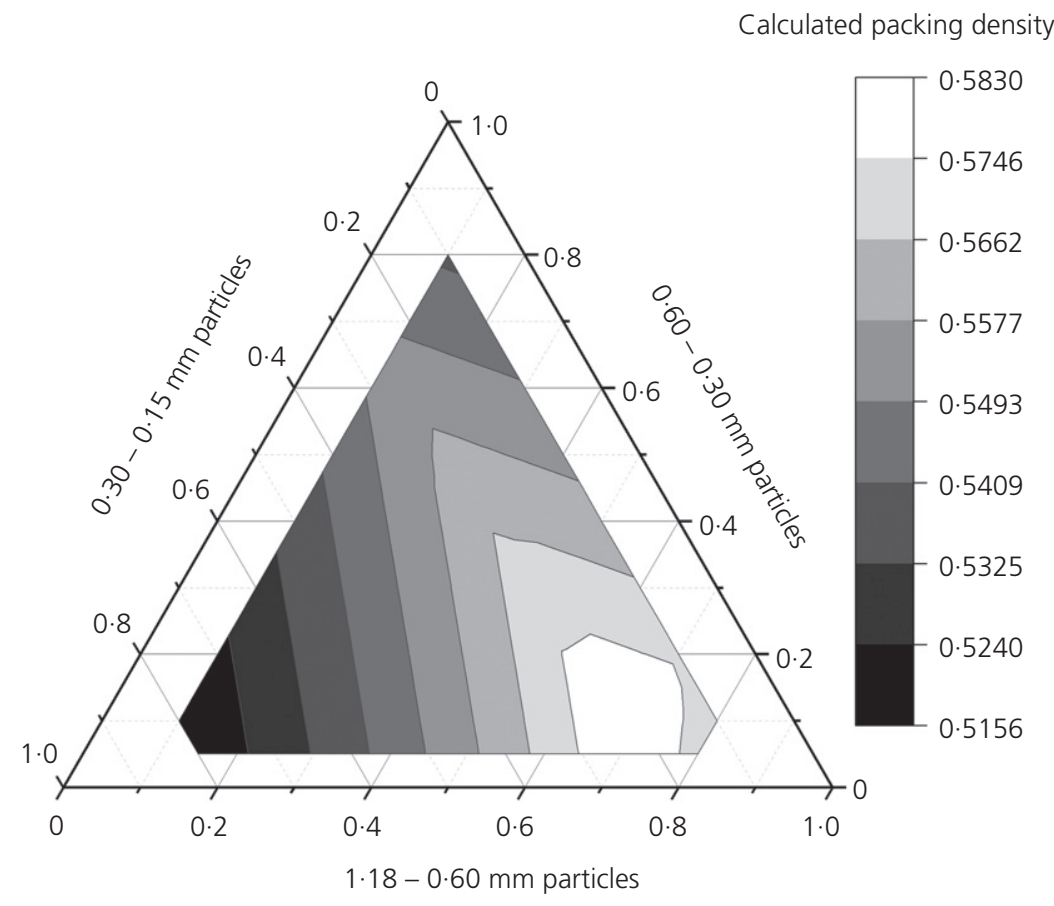

Figure 3. Calculation of packing density using Matlab 


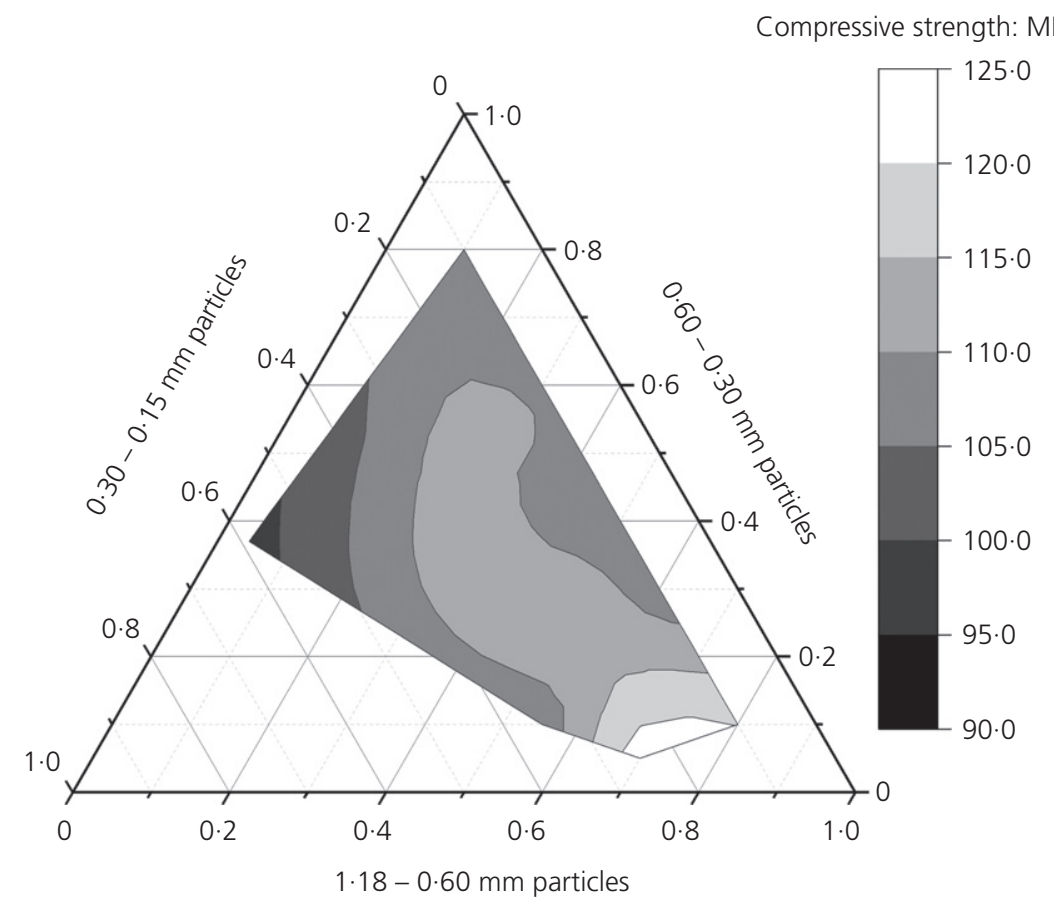

Figure 4. Compressive strength results

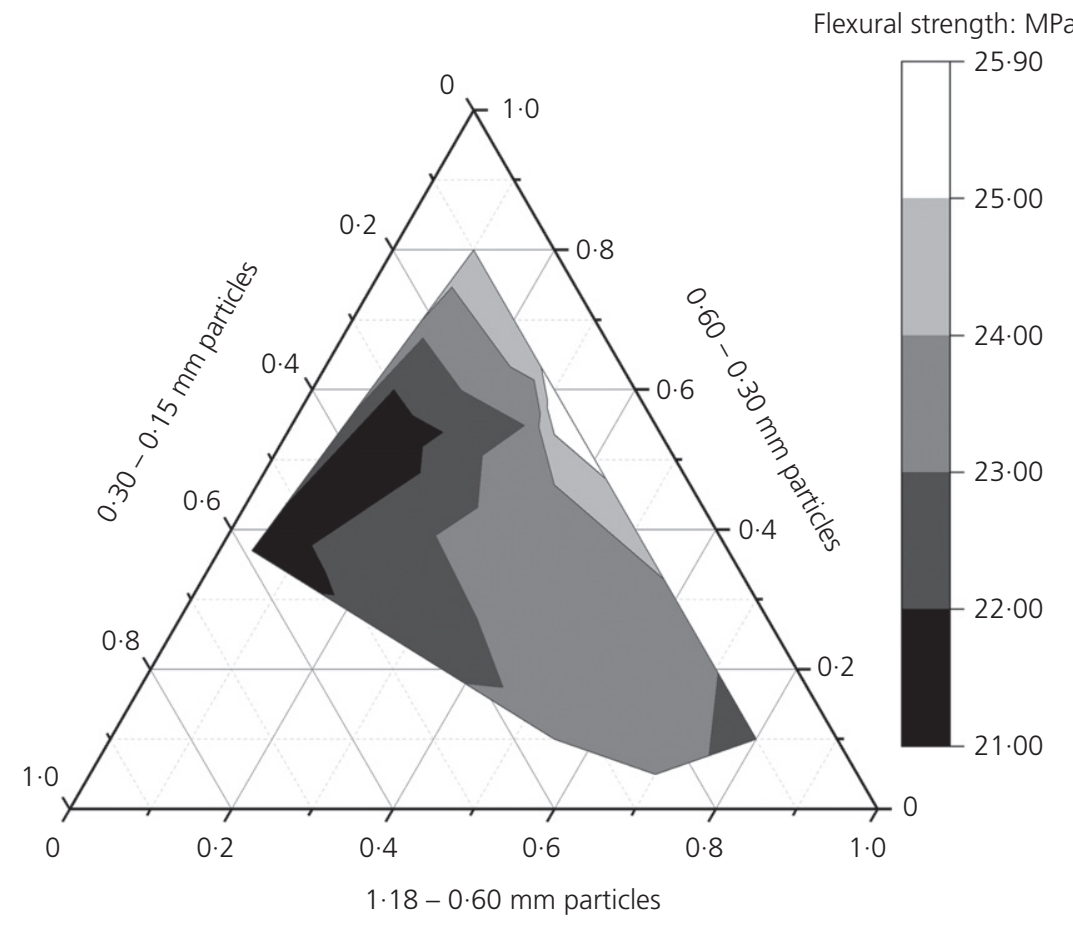

Figure 5. Flexural strength results

The interface length (aggregate perimeter) between the cement and aggregate was then calculated using Image-Pro Plus software.
The interface lengths of the three specimens (total length of interface per square millimetre) are shown in Figure 7 and the cumulative distribution of interface lengths is shown in 
Table 6. Packing densities and strengths of UHPC made with three typical sand gradations

\begin{tabular}{|c|c|c|c|c|c|c|}
\hline & & Sand proportio & & & & \\
\hline & $1.18-0.6 \mathrm{~mm}$ & $0.6-0.30 \mathrm{~mm}$ & $0.30-0.15 \mathrm{~mm}$ & Packing density & Compressive strength: $\mathrm{MPa}$ & Flexural strength: $\mathrm{MPa}$ \\
\hline C1 & 0.70 & 0.05 & 0.25 & 0.5852 & 124.0 & $23 \cdot 1$ \\
\hline C2 & $0 \cdot 30$ & 0.60 & $0 \cdot 10$ & 0.5525 & $106 \cdot 8$ & $25 \cdot 9$ \\
\hline C3 & 0.04 & $0 \cdot 37$ & 0.59 & 0.5272 & $98 \cdot 0$ & $21 \cdot 5$ \\
\hline
\end{tabular}
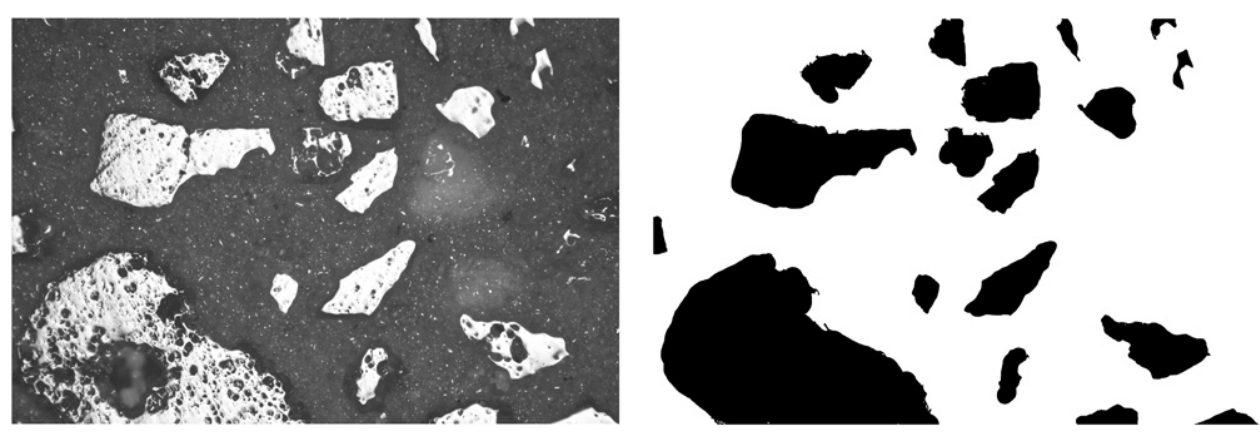

Figure 6. Image analysis process

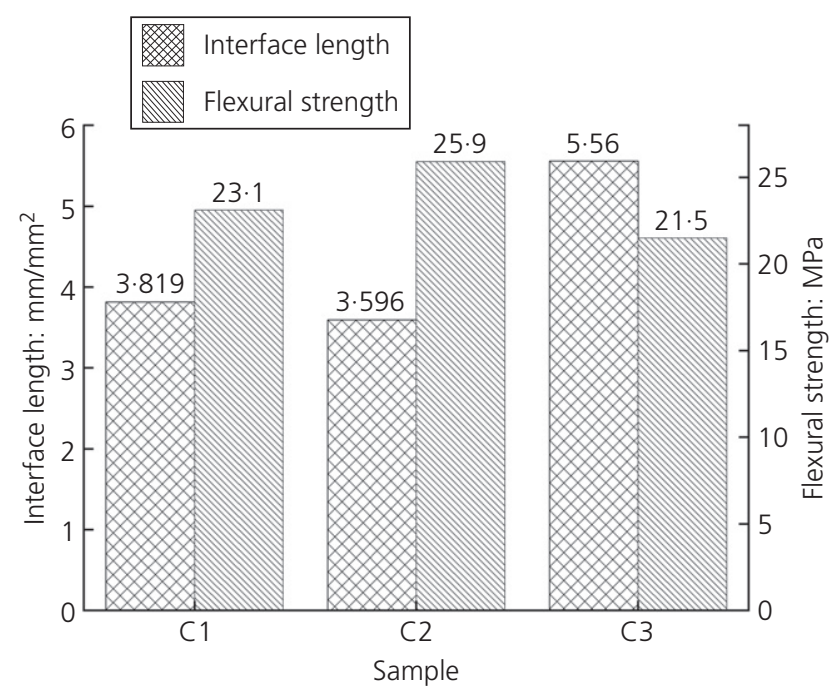

Figure 7. Interface length and flexural strength results

Figure 8. Figure 7 shows that the packing density of the three gradations was not positively correlated with the UHPC interface length. However, it can be seen from Table 6 that the compressive strength had a good positive correlation with the packing density of the quartz sand, which was consistent with the previous results. This indicates that the compressive strength mainly depended on the sand packing density.

Comparison of the flexural strength of the three gradations with the interface length (see Figure 7) reveals that the larger

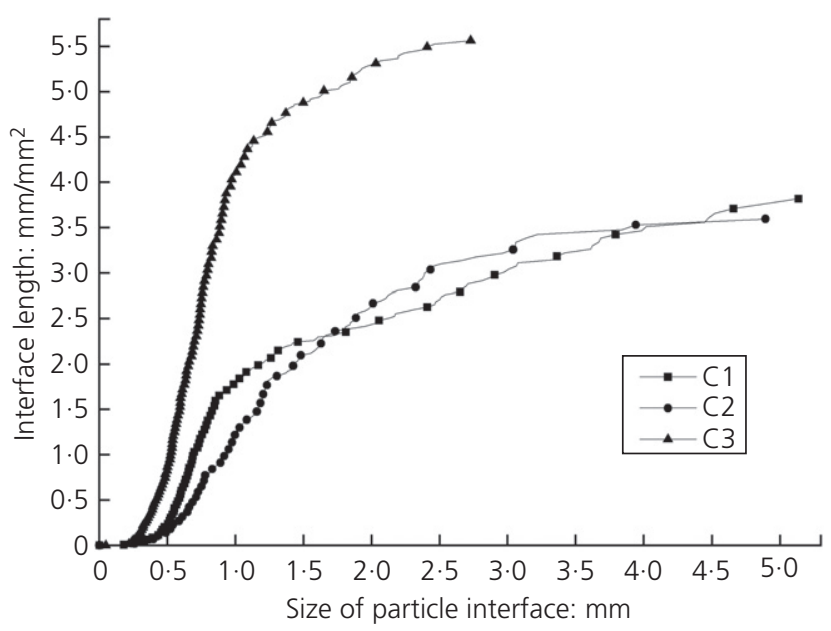

Figure 8. Cumulative distribution of interface lengths

the interface length, the lower the flexural strength. The interface length of $\mathrm{C} 3$ was the largest (up to $5.56 \mathrm{~mm} / \mathrm{mm}^{2}$ ) and its flexural strength was the lowest $(21.5 \mathrm{MPa}) . \mathrm{C} 2$ had the smallest interface length $\left(3.596 \mathrm{~mm} / \mathrm{mm}^{2}\right)$ and the greatest flexural strength $(25.9 \mathrm{MPa})$. It can thus be inferred that the flexural strength of concrete is particularly sensitive to the number of internal interfaces. This is because the larger the interface, the more weak points there are and thus the lower the flexural strength. As shown in Figure 8, the more sand particles of size $0 \cdot 30-0 \cdot 15 \mathrm{~mm}$ in the mix, the larger the slope of the curve and the greater the interface length. Therefore, when preparing UHPC, the proportion of sand 
particles of size $0 \cdot 30-0 \cdot 15 \mathrm{~mm}$ should be reduced to ensure high flexural strength.

\section{Conclusions}

Based on the experimental results, the following conclusions can be drawn:

- Correcting the CPM with the equation $Y=0 \cdot 60073 X+0 \cdot 20551$, which was found to calculate the packing density of quartz sand accurately, can eliminate the influence of the aggregate shape factor.

- The flexural strength of UHPC was found to be particularly sensitive to aggregate interfaces. As the number of interfaces increased, the flexural strength decreased. The specimen with the largest interface length $\left(5.56 \mathrm{~mm} / \mathrm{mm}^{2}\right)$ had the lowest flexural strength $(21.5 \mathrm{MPa})$ and the specimen with the smallest interface length $\left(3.596 \mathrm{~mm} / \mathrm{mm}^{2}\right)$ had the highest flexural strength (25.9 MPa).

- The results of this study also showed that a higher packing density of quartz sand led to a higher UHPC compressive strength. By increasing the packing density, the compressive strength of the UHPC was increased from $97.9 \mathrm{MPa}$ to $124 \cdot 1 \mathrm{MPa}$ - an increase of $26.7 \%$. Thus, when designing aggregate gradations, a gradation with a high packing density should be selected and the proportion of aggregate of small particle size should be reduced.

- The use of Matlab to design aggregate gradation has many advantages, such as a small amount of tests and excellent results. It can thus be used as a new method for designing aggregate gradation.

The next step of this work will be to establish a model for particle size distribution and interface length that can accurately calculate the interface length of UHPC. Furthermore, the factors influencing strength need to be further examined. The method of designing aggregate gradations could also be extended to ordinary concrete.

\section{Acknowledgment}

The authors would like to acknowledge the National Natural Science Foundation of China for financial support (no. 21466023) to this work.

\section{REFERENCES}

Abyaneh SD, Wong H S and Buenfeld NR (2013) Modelling the diffusivity of mortar and concrete using a three-dimensional mesostructure with several aggregate shapes. Computational Materials Science 78: 63-73.

Achour T, Loulizi A and Achour R (2019) Mechanical characterisation of aggregates using concrete compressible packing model. European Journal of Environmental and Civil Engineering 23(8) 945-956

Arora A, Yao Y, Mobasher B and Neithalath N (2019) Fundamental insights into the compressive and flexural response of binder-and aggregate-optimized ultra-high performance concrete (UHPC) Cement \& Concrete Composites 98: 1-13.

Bala M, Zentar R and Boustingorry P (2019) Parameter determination of the compressible packing model (CPM) for concrete application. Powder Technology 367(1): 56-66.

Bolomey J (1927) Determination of the compressive strength of mortar sand concrete. Bulletin Technique de la Suisse Romande 16: $22-24$.

Chen S, Zhang R, Jia LJ and Wang JY (2017) Flexural behaviour of rebar-reinforced ultra-high-performance concrete beams. Magazine of Concrete Research 70(19): 997-1015, https://doi.org/10.1680/ jmacr.17.00283.

CNS (China National Standards) (1999) GB/T 17671: Method of testing cements - determination of strength. Standardization Administration of China, Beijing, China.

CNS (2011) GB/T 14684: Sand for building. Standardization Administration of China, Beijing, China.

De Larrard F (1999) Concrete mixture proportioning: a scientific approach. Beijing Review 55: 2-2.

Fuller WB and Thompson SE (1907) The laws of proportioning concrete. Transactions of the American Society of Civil Engineers LIX(2): 67-143.

Ghasemi Y, Rajczakowska M, Emborg M and Cwirzen A (2018) Shape-dependent calculation of specific surface area of aggregates versus X-ray microtomography. Magazine of Concrete Research 72(2): 88-96, https://doi.org/10.1680/jmacr.18.00121.

Han B, Liu MH, Xie HB and Liu YP (2016) A strength developing model of concrete under sustained loads. Construction and Building Materials 105(15): 189-195.

Kwan AK, Mora CF and Chan HC (1999) Particle shape analysis of coarse aggregate using digital image processing. Cement and Concrete Research 29(9): 1403-1410.

Maerz NH (2004) Technical and computational aspects of the measurement of aggregate shape by digital image analysis. Journal of Computing in Civil Engineering 18(1): 10-18.

Moghaddam TB and Baaj H (2018) Application of compressible packing model for optimization of asphalt concrete mix design. Construction and Building Materials 159(20): 530-539.

Mora CF and Kwan AKH (2000) Sphericity, shape factor, and convexity measurement of coarse aggregate for concrete using digital image processing. Cement and Concrete Research 30(3): 351-358.

Prudêncio LR, Weidmann DF, de Oliveira AL and Damo GF (2013) Particle shape analysis of fine aggregate using a simplified digital image processing method. Magazine of Concrete Research 65(1): 27-36, https://doi.org/10.1680/macr.11.00199.

Roquier G (2017) The 4-parameter compressible packing model (CPM) for crushed aggregate particles. Powder Technology 320: 133-142.

Shilstone JM (1990) Concrete mixture optimization. Concrete International 12(6): 33-39.

Shilstone JM and Shilstone JM (2002) Performance-based concrete mixtures and specifications for today. Concrete International 24(2): $80-83$.

Talbot AN, Brown HA and Richart FE (1923) The Strength of Concrete: its Relation to the Cement Aggregates and Water. University of Illinois at Urbana Champaign, Champaign, IL, USA, Bulletin No. 137.

Thirumalaiselvi A, Anandavalli N and Rajasankar J (2018) Mesoscale studies on the effect of aggregate shape idealisation in concrete. Magazine of Concrete Research 71(5): 244-259, https://doi.org/ 10.1680/jmacr.17.00184.

Van Der Putten J, Dils J, Minne P, Boel V and De Schutter G (2017) Determination of packing profiles for the verification of the compressible packing model in case of UHPC pastes. Materials and Structures 50(2): 118.

Vincler JP, Sanchez T, Turgeon V, Conciatori D and Sorelli L (2019) A modified accelerated chloride migration tests for UHPC and 
UHPFRC with PVA and steel fibers. Cement and Concrete Research 117: 38-44.

Weymouth CA (1933) Effects of particle interference in mortars and concretes. Rock Products 36(2): 26-30.

Xu Y, Liu J, Liu J, Zhang Q and Zhao H (2018) Creep at early ages of ultrahigh strength concrete: experiment and modelling. Magazine of Concrete Research 71(16): 847-859, https://doi.org/10.1680/ jmacr.17.00551.

Yuan G, Hao P, Li D, Pan J and Dong S (2020) Optimization design and verification of large stone porous asphalt mixes gradation using compressible packing model. Construction and Building Materials 230(10): 116903.

\section{How can you contribute?}

To discuss this paper, please submit up to 500 words to the editor at journals@ice.org.uk. Your contribution will be forwarded to the author(s) for a reply and, if considered appropriate by the editorial board, it will be published as a discussion in a future issue of the journal. 